\title{
COMMUNITY DEVELOPMENT IN THE EAST PREFECTURE OF ATTICA, GREECE, FOLLOWING THE 2004 SUMMER OLYMPIC GAMES OF ATHENS
}

\author{
H. THEODOROPOULOU, M. VAMVAKARI \& R. MITOULA \\ Department Home Economics \& Ecology, Harokopio University of Athens, Greece.
}

\begin{abstract}
The present study examined how community development has been affected by social and economic changes in four specific semi rural areas which are located in the east prefecture of Attica in Greece. These semi rural areas are affected significantly by social and economic changes, because of substantial new infrastructure development that took place in relation to the 2004 Summer Olympic Games of Athens. The aim of this study was to examine local entrepreneurship as well as local social and economic development in the study areas. Sample data were collected on the characteristics of residents and local enterprises and land use changes in these four areas of Attica. On the basis of these data a profile of the residents and the characteristics of land use and local enterprises were constructed. The results of the study showed that there has been a substantial population increase and real estate construction. Also, residential land has increased at the expense of farmland. Furthermore, new enterprises are founded through private investments, which increase local entrepreneurship. Using cross-tabulation statistical methods it was found that the educational level of the responders is positively related with the occupation satisfaction $(P=0.0345)$. Also, the more an area was developed the more pharmacies existed in the specific area $(P=0.0437)$ and the closest an area was from the sea the more tourist character it had $(P=0.0000)$. In addition, the analysis of the logistic regression models showed that as private investment and urban planning increase local development increases, while as population density increases local development decreases $(R=81.2 \%)$. Furthermore, the more social services exist in a community such as help at home, shelter for elderly and there are more chances for employment then local sustainable development is increased In addition, as the number of homeless people increases local sustainable development decreases. $(R=80.2 \%)$. Also, Kruskal-Wallis $H$ - tests were performed for the comparison of the four areas concerning demographical and residential elements as well as development elements, which showed that the opinion of the respondents from all four areas is similar as regards quality of life and job satisfaction at $\alpha=1 \%$ significance level.
\end{abstract}

Keywords: community, development, enterprises, local, sustainable.

\section{INTRODUCTION}

An important approach to the study of communities is the structural community development position that communities are not individuals but systems of community institutions. Central themes in structural analysis of communities include differentiation, centrality and solidarity [1]. Differentiation of communities is the pattern of institutions in a community like schools, universities, hospitals, hotels, recreation facilities, etc. Young and others have found that there is a connection between the presence of various institutions and services in a community and they do not appear randomly. For instance, the presence of medical services in a community is linked to the presence of pool halls and hotels. Therefore, the differentiation of a community is the result of its makeup and not the result of individual actions.

Centrality describes the degree of connection of a community to the external world. The centrality of a community can range from the lowest level, as that of a remote settlement, to the highest level of centrality, as that of a metropolitan centre. While generally centrality increases as differentiation increases, these variables are separate dimensions of community structure and they can vary independently. 
Solidarity is a system of values, ethics, standards and guidelines that keep the community together. Solidarity can also range from low to high, and a minimum amount of solidarity is needed to keep together a community with a given amount of differentiation. Therefore, social structure and human agency play important roles in community development. Humans, like other beings, must compete for a spatial niche in the larger habitat. This competition gives rise to a struggle in which each type of land user ends up in the location to which the user is best adapted [2-5].

Differentiation, centrality and solidarity in a community are appropriate variables to define if there is local sustainable development in a community as well. More specifically, variables which describe the differentiation of a community such as population density, number of schools, daycare centres, hospitals, parks or describe the centrality of a community such as the distance from a city, private investment, or the solidarity such as values and customs, respect for the environment could also be used to define local development [2, 6-13]. Another way of defining local development is to observe whether community construction follows sustainable city construction planning, for example whether there are enough parks, playgrounds and green areas per resident [14-18]. Another variable which can define local development is easy access to information and new technology, for example access to the Internet brings users close to any new development; therefore, the Internet is an indicator of local development $[19,20]$. Moreover, the existence of health centres in a community is an essential factor of local development. Distance from a health centre decreases the degree of local development of a community [21, 22]. Based on the above theoretical analysis using the described variables, an empirical study was performed to determine whether there is potential for local development in east Attica.

In addition, in structuralism, social changes in communities and regions are seen as a naturally occurring process, but sustainable community development is dependent on several socio-economic policies such as compensation, health, environmental, infrastructure, housing, tourism services, etc. For example, family planning is believed to be an important social policy that can influence development [23-27]. Also, economic measures of employment, income or production can affect local sustainable development over time [3,28-30]. City planning measures which could be related to the city's habitants' demographic characteristics such as age, gender, education, culture, etc. can affect sustainable community development [31-36].

The main aim of the current policy and action of the European Union is sustainable development of its cities or local sustainable development. The principal sectors which are supported by the European Union and are the subject of intervention measures towards sustainability are transport networks, energy networks, new technologies in telecommunications and informatics, the development of technology, creation of jobs and support of enterprises, protection of the environment, support of tourism and promotion of the European cultural heritage, rural and urban development, social welfare services through specific programmes such as help at home for elders, and support of children by establishments like children's daycare and playgrounds. These sectors, which are similar to the central themes in the structural analysis of communities as described above, are related directly or indirectly to sustainability of a city [37-40]. We used the variables described above to identify and characterise local sustainable development in the study area.

Community theory today is attempting to discover, describe and understand the interaction between mass society and the local community. Better understanding of the theoretical base of this interaction will provide the potential for exploring solutions, which will improve the quality of communal life or will increase the local sustainable development [4].

During the last 5 years, substantial new infrastructure development took place in the east prefecture of Attica in Greece, which is accountable for changing the structure of the communities in this area from semi rural to semi urban. Differentiation, centrality and solidarity of those areas are changing 
causing the adjustment of communal life under the new circumstances. The most important structures that developed and changed the character of the study area were related to the 2004 Summer Olympic Games of Athens including a new high-speed road (Attiki Odos) that joined the city of Athens with these areas, the new Athens International Airport, a health centre with urban character, modern athletic, stallion and gun shooting centres, new schools, renovation of existing parks and beaches and finally many social programmes. In view of the fact that these areas are now more accessible from the city of Athens, many people, who work in the city of Athens, choose and commute and live in those semi rural areas, searching for better living conditions. The result is that there is an increasing demand for housing and the character of the land is changing from that of farms to residential areas. The increasing population and housing development without a specific growth plan can have a negative effect on local sustainable development.

The aim of the present study was to examine and illustrate the current socio-economical development in four specific areas of the east prefecture of Attica in Greece and to find the specific sectors (indicators) which could contribute to local sustainable development.

\section{MATERIALS AND METHODS}

Four areas located in the east prefecture of Attica in Greece were examined. The characteristics of these areas based on the 2001 census (www.ypes.gr) were as follows. The municipality of Vari is a 2500-year-old city with a population of 10998 and an area of $22189 \mathrm{~m}^{2}$ which is mostly semi rural. The municipality of Kalivia is a semi mountainous area at an altitude of $110 \mathrm{~m}$ above sea level with a population of 12202 and an area of $70415 \mathrm{~m}^{2}$. The municipality of Koropi has a population of 25325 and covers a rural area of $120000 \mathrm{~m}^{2}$. Finally, the municipality of Markopoulo has a population of 15605 and covers $81844 \mathrm{~m}^{2}$. Since ancient times the main production of these areas was grapes and wine.

The statistical frame of the study was based on a sample of 192 residents randomly selected from the four regions of east Attica. More specifically, 33 questionnaires were selected from Vari, 37 from Kalivia, 75 from Koropi and 47 from Markopoulo, which represents $0.3 \%$ of the population of each area. The census bureau had no available data on the demographic, social and economic characteristics of residents along with their entrepreneurship preferences. Therefore, relevant data were collected through a questionnaire survey during the spring of 2005. The investigators completed the questionnaires by visiting a random sample of residents who agreed to participate in the study and directly interviewing them in order to avoid misunderstanding in the completion of the questionnaires. The questionnaire comprised 87 closed questions with pre-coded replies on 17 subjects: demography, infrastructure, access to information, health, housing, social welfare, education, employment, transportation, tourism, agriculture, livestock farming, fisheries, environmental protection, new technology transfer, real estate development, projects funded by EU. The questionnaire is available by e-mail upon request.

The data collected were analysed by using descriptive statistics for calculating the means and standard deviations of continuous variables and the frequencies and percentages of discrete variables. Data elaboration and statistical analysis were performed using SPSS10, logistic regression models $(\ln (p / 1-p)=a+b X)$ were used to explain variations of local development, as well as resident's responses to the questions on the subjects described above.

Logistic regression was used because it is useful for predicting the presence or absence of a characteristic or outcome based on values of a set of predictor variables and it is suited to models where the dependent variable is dichotomous. Kruskal-Wallis $H$ - tests were performed for the comparison of the four areas concerning demographical and residential elements as well as development elements. Finally, cross-tabulations were made between related responses and the chi-square $\left(\chi^{2}\right)$ test 
of independence was used for statistical comparisons among them. We are reporting all significant dependencies where their $P$-values are $<\alpha=0.05$, our standard significant level.

\section{RESULTS}

\subsection{Descriptive and cross-tabulation statistical methods}

Not all of the 87 questions were answered by every respondent. Based on the data analysis of the 192 questionnaires the majority of respondents were men (54\%) and their age ranged from 29 to 38 years $(33 \%)$. Most of the respondents were married $(65 \%)$ and the average number of children per married respondent was two. Most of the individuals were self-employed (38\%), or employed in the private sector $(12 \%)$ or they were housekeepers and retirees $(20 \%)$. Their education level was mostly high school (31\%), while $28 \%$ had finished university. Also, according to the analysis of the data on infrastructure most of the respondents (89\%) were living in houses in legal residential areas. Most of the individuals (54\%) had connection to the Internet. Only $16 \%$ of the total study areas had connection to a central sewage system but there were water supply plumbing facilities everywhere. Also, $46 \%$ of the respondents replied that there were playgrounds close to their houses, $51 \%$ that there was a health centre less than $1 \mathrm{~km}$ from their houses and $22.9 \%$ that there were at least three pharmacies close to their house. Most of the respondents (99\%) replied that there was a centre for elders in their area, $77 \%$ that there was a programme through the municipality for help at home, but $60 \%$ of the respondents replied that there is some or no access to public places for people with special needs. Most $(91 \%)$ of the residents owned a house or apartment and $66 \%$ reside close to their work. Real estate construction has increased in the study area (44\%) and mainly new construction is happening where farms used to be before the 2004 Olympic games of Athens.

Furthermore, using cross-tabulation statistical methods it was found that the educational level of the respondents is positively related to occupation satisfaction $(P=0.0345<\alpha=0.05)$, that is the more educated the residents were the more they reported that they were satisfied with their occupation. Also, it was found that the more an area was developed the more pharmacies existed in the specific area $(P=0.0437<\alpha=0.05)$. Also, there was a positive relationship between the distance of an area from the sea and the tourist character of this area that is tourist areas were those that are close to the sea $(P=0.0000<\alpha=0.01)$.

\subsection{Binary logistic regressions}

Initially, a binary logistic regression was analysed to investigate the direct effects of local characteristic variables on the local development of the study areas. The dependent variable was measured based on the sample's responses to a two-point scale: yes/no to the following statement: 'If local development has been accomplished'. The independent variables included private investment and local characteristics. Table 1 describes the independent variables that were used to define whether there is local development.

The equation for the effects of local characteristics variables on the local development of the study areas is as follow:

$$
\begin{aligned}
\ln (\text { Local development })= & 3606+1516 \times(\text { Private investment })-1108 \times(\text { Population density }) \\
& -0.418 \times(\text { Environment deterioration }) \\
& +0.817 \times(\text { City planning measures }) \\
& +0.258 \times(\text { Internet access })-0.087 \times(\text { Hospital vicinity }) .
\end{aligned}
$$


Table 1: List of independent variables used in the local development logistic regression model.

\begin{tabular}{lll}
\hline Variable & Type & Description \\
\hline Private investment & Nominal & 1 if there is private investment in the area; 0 otherwise \\
Population density & Ordinal & $1=$ Very crowded, 2=less crowded, $3=$ not at all \\
Environment deterioration & Ordinal & $1=$ Very high, $2=$ high, $3=$ moderate, $4=$ not present \\
City planning measures & Nominal & 1 for areas where there is urban planning; 0 otherwise \\
Internet access & Nominal & 1 if there is Internet access; 0 otherwise \\
Hospital vicinity & Scale & How close is a hospital $(\mathrm{km})$ \\
\hline
\end{tabular}

Table 2: List of variables used in the local sustainable development logistic regression model.

\begin{tabular}{|c|c|c|}
\hline Variable & Type & Description \\
\hline Homeless & Nominal & 1 if there are homeless people in the area; 0 otherwise \\
\hline Help at home & Nominal & $\begin{array}{l}1 \text { if there is a social programme for help at home; } \\
0 \text { otherwise }\end{array}$ \\
\hline Playgrounds & Nominal & 1 if there are many/enough playgrounds; 0 otherwise \\
\hline Shelter for elder & Nominal & 1 if there is a shelter for elder; 0 otherwise \\
\hline Chances for employment & Nominal & $\begin{array}{l}1 \text { if there are lot of/ adequate chances for employment; } \\
0 \text { otherwise }\end{array}$ \\
\hline Public transportation & Ordinal & $\begin{array}{l}1=\text { there is public transportation accessibility and adequate } \\
\text { infrastructure, } 2=\text { some, } 3=\text { none }\end{array}$ \\
\hline Plumbing facilities & Nominal & $1=$ if the plumbing facilities are adequate; $0=$ otherwise \\
\hline
\end{tabular}

The analysis of the above logistic regression model showed that $81 \%$ of the variance of Local development was significantly explained by the local characteristic variables. Specifically, Local development was significantly associated with Private investment, Population density and City planning measures $(* P<0.10)$. That is, in areas with private investments there is a higher probability for local development than in the areas where there are no private investments. Also, areas with high population density have a lower probability for local development than areas with lower population density. Finally, in areas where there are city planning measures there is a higher probability for local development.

A second binary logistic regression was conducted to investigate the direct effects of local characteristic variables on local sustainable development of the study area. The dependent variable was measured based on the sample's responses to a two-point scale: yes/no to the following statement: 'If your area is a sustainable area'. The independent variables included amount of homeless people, social programmes and public services (Table 2).

The equation for the effects of local characteristics variables on the local sustainable development as the follows:

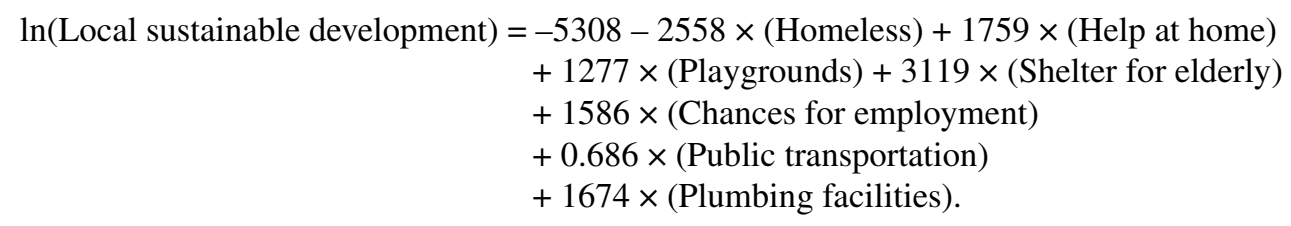


The analysis of the above logistic regression model showed that $80 \%$ of the variance of Local sustainable development was significantly explained by the local characteristic variables.

Specifically, Local sustainable development was significantly associated with Homeless and Help at home, Shelter for elder and Chances for employment $(* P<0.05)$. These results suggest that areas with social programmes such as Help at home, Shelter for elderly and Chances for employment have a higher probability for Local Sustainable development. On the other hand, areas with homeless have a low probability for Local Sustainable development.

3.3 Comparison of demographic, residential and development data in the four municipalities in the study area

Table 3 represents responses to questions about residents' attitudes and beliefs about several demographic characteristics of their municipalities. On a three-point score respondents indicate whether their municipality is high, medium or low on recreational facilities, distance from work, distance to hospitals, building new residences, income satisfaction and unemployment. The table shows that the respondents believe that their community has high standards as regards recreational facilities and construction. On the other hand, they say that they must travel a long distance to work, but they are satisfied with their income from work, and they believe unemployment is low. They note that access to hospitals is neither near nor far but in the middle range. Finally, they note that new home construction is high in the community.

The results in Table 4 mainly support what is shown in Table 3 but there are some additional clarifications related to demographic and residential characteristics of the four municipalities. More specifically, Table 4 presents the percentages of the responses to questions related to residential characteristics of the four municipalities in the study area on a three-point scale $(3=$ strongly agree, 2 = fairly agree, $1=$ disagree). Responses for a sustainable city, local development and if there is illegal construction of housing score a strong per cent of agreement, while responses for satisfaction from infrastructure, green areas and if the area is overpopulated score a fairly moderate per cent of agreement and responses for job satisfaction score a low per cent of agreement. Residents, even if they observe there is a lot of illegal construction in their communities, believe that they reside in a sustainable area where there is local development mainly because their area is still not so overpopulated and there is moderate infrastructure and green in comparison with other nearby areas. It is also observed that job satisfaction is low but it is not affecting residents' opinion of local development because they believe that job availability will bring more people in the area, which will deteriorate local sustainable development. We interpret to mean that they prefer to commute to their jobs and to reside in a not overpopulated community.

Table 5 compares if there are similarities on demographic and residential variables among the four municipalities. The four municipalities are similar at $a=5 \%$ significance level according to the variables: number of bedrooms per person, distance from work, monthly income and duration of unemployment. For the rest of the variables there is no resemblance at $a=5 \%$.

In Table 6 a comparison of data on development for the four municipalities is presented. In columns $2-5^{\mathrm{h}}$ the measures mean $\pm \mathrm{SD}$ of the concerned variables for the four municipalities are given. With these measures the four municipalities are compared.

The last column gives the $P$-values for the Kruskal-Wallis $H$-test. The four municipalities are similar according to the variables job satisfaction and sustainable city. Moreover, the four municipalities are similar according to the variable of satisfaction from green at $a=1 \%$ significance level. For the remaining variables there is no resemblance at $a=5 \%$. 
Table 3: Percentages of the responses to questions related to demographic and residential characteristics of the four municipalities in the study area on a three-point scale $(3=$ high, 2 = medium, 1 = low).

\begin{tabular}{|c|c|c|c|c|c|c|}
\hline Variables (parameters) & $\begin{array}{l}\text { High } \\
(\%)\end{array}$ & $\begin{array}{l}\text { Medium } \\
(\%)\end{array}$ & $\begin{array}{l}\text { Low } \\
(\%)\end{array}$ & $n$ & $M$ & SD \\
\hline $\begin{array}{l}\text { Communal recreational facilities: play grounds, } \\
\text { pools, sport grounds } \\
\text { (High = many facilities } \\
\text { Medium = enough facilities } \\
\text { Low = very few or no facilities) }\end{array}$ & 38 & 33.9 & 28.1 & 192 & 2.10 & 0.81 \\
\hline $\begin{array}{l}\text { Distance from work } \\
\text { (High = the job is in the community } \\
\text { Medium = the job is close to the } \\
\text { residence community } \\
\text { Low = the job is far from the community) }\end{array}$ & 21.3 & 12.9 & 65.8 & 155 & 1.55 & 0.82 \\
\hline $\begin{array}{l}\text { Distance from hospital } \\
(\text { High } \leq 2 \mathrm{~km} \\
\text { Medium }=2-5 \mathrm{~km} \\
\text { High } \geq 5 \mathrm{~km})\end{array}$ & 22.9 & 66.1 & 10.9 & 192 & 2.12 & 0.57 \\
\hline $\begin{array}{l}\text { Construction of new residences } \\
\text { (High = there are a lot of new constructions } \\
\text { Medium = there are few new construction } \\
\text { Low = there some or no new constructions) }\end{array}$ & 44.3 & 40.3 & 14.8 & 192 & 2.30 & 0.71 \\
\hline $\begin{array}{l}\text { Satisfaction from income } \\
\text { (High = very satisfied } \\
\text { Medium =satisfied enough } \\
\text { Low = not satisfied) }\end{array}$ & 44.9 & 40.3 & 14.8 & 176 & 2.30 & 0.71 \\
\hline $\begin{array}{l}\text { Years of unemployment } \\
\text { (High }=\text { more than } 2 \text { years } \\
\text { Medium }=6 \text { months up to } 2 \text { years } \\
\text { Low }=\text { up to } 6 \text { months) }\end{array}$ & 10.4 & 17.2 & 72.4 & 192 & 1.37 & 0.66 \\
\hline
\end{tabular}

$n$, number of responses; $M$, sum of scores $/ n(1 \leq M \leq 3 ; M \geq 1.5$ : medium and high level); $\mathrm{SD}$, standard deviation.

\section{CONCLUSIONS}

The strategic priorities currently set by the European Union (peripheral competitiveness, employment and social cohesion, etc.) affect significantly the form and physiognomy of rural as well as urban areas of Greece. Particularly, development is decisively affected by the actions of the general policy regarding local sustainable development, which tries to promote local development.

In the present study, factors that were found to affect local sustainable development were population density, private investment and city planning measures. Furthermore, it was found that the number of homeless people, the access to social services and chances for employment affect local sustainable development. We found that an increase in various institutions and services in a 
Table 4: Percentages of the responses to questions related to residential characteristics of the four municipalities in the study area on a three-point scale $(3=$ strongly agree, $2=$ agree, $1=$ disagree $)$.

\begin{tabular}{lcccccc}
\hline Questions & $\begin{array}{c}\text { Strongly } \\
\text { agree } \\
\text { (variables) }\end{array}$ & $\begin{array}{c}\text { Agree } \\
(\%)\end{array}$ & $\begin{array}{c}\text { Disagree } \\
(\%)\end{array}$ & $n$ & $M$ & SD \\
\hline Job satisfaction & 32.7 & 27.2 & 40.1 & 162 & 2.07 & 0.85 \\
Satisfaction from roads & 22.4 & 49.5 & 28.1 & 192 & 2.06 & 0.71 \\
Adequacy of mass transportation & 33.3 & 33.3 & 33.3 & 192 & 2.00 & 0.82 \\
Satisfaction from green areas & 34.9 & 63.5 & 1.6 & 192 & 2.33 & 0.50 \\
Sustainable city & 89.1 & 9.9 & 1 & 192 & 2.88 & 0.36 \\
Illegal construction & 46.4 & 40.1 & 13.5 & 192 & 2.33 & 0.70 \\
Local development & 81.8 & 17.1 & 0.5 & 192 & 2.81 & 0.40 \\
Over-populated region & 13.5 & 67.5 & 19.3 & 192 & 1.94 & 0.57 \\
\hline
\end{tabular}

$n$, sample size; $M$, sum of scores/n $(1 \leq M \leq 3 ; M \geq 1.5$ : strongly/fairly agree); SD, standard deviation.

Table 5: Comparison of responses on the demographic and residential variables among the four municipalities.

\begin{tabular}{lccccc}
\hline $\begin{array}{l}\text { Questions } \\
\text { (variables) }\end{array}$ & $\begin{array}{c}\text { Vari } \\
(33)\end{array}$ & $\begin{array}{c}\text { Kalivia } \\
(37)\end{array}$ & $\begin{array}{c}\text { Koropi } \\
(75)\end{array}$ & $\begin{array}{c}\text { Markopoulo } \\
(47)\end{array}$ & $P$-value $^{\dagger}$ \\
\hline Type of residence & $1.64 \pm 0.5^{* *}$ & $2.52 \pm 0.13$ & $2.14 \pm 0.10$ & $1.81 \pm 0.13$ & 0.000 \\
Number of bedrooms & $1.91 \pm 0.10$ & $2.17 \pm 0.10$ & $2.31 \pm 0.081$ & $2.05 \pm 0.10$ & 0.536 \\
Distance from work & $1.64 \pm 0.16$ & $1.66 \pm 0.16$ & $1.55 \pm 0.12$ & $1.46 \pm 0.13$ & 0.396 \\
Distance from hospital & $2.45 \pm 0.11$ & $1.93 \pm 0.12$ & $2.20 \pm 0.079$ & $1.86 \pm 0.791$ & 0.000 \\
Constr. of new residences & $1.55 \pm 0.19$ & $2.00 \pm 0.15$ & $2.14 \pm 0.093$ & $1.51 \pm 0.14$ & 0.000 \\
Height of monthly income & $2.41 \pm 0.17$ & $2.55 \pm 0.2$ & $2.43 \pm 0.089$ & $2.38 \pm 0.11$ & 0.243 \\
Duration of unempl. & $1.55 \pm 0.17$ & $1.28 \pm 0.11$ & $1.39 \pm 0.008$ & $1.54 \pm 0.12$ & 0.194 \\
\hline
\end{tabular}

*Kruskal-Wallis $H$ - test (a nonparametric test equivalent to one-way ANOVA to test whether our four independent samples are from the same population).

${ }^{\dagger}$ Mean \pm SD.

community is linked to local sustainable development, while an increase in homeless and population density is linked to local deterioration.

The results show that differentiation, centrality and solidarity of the studding area are changing due to adjustment of life to new circumstances. Specifically, the population boom in the municipalities of Bari, Kalivia, Koropi and Markopoulo has increased social and cultural diversity. We found that increasing private investment led to the founding of new stores and enterprises, which in turn led to the expansion of public and private services like banks, health centres, coffee shops, restaurants, infrastructure and transportation. All the above and in addition, the new high-speed road that joined the city of Athens with these areas caused more people to seek employment or just to reside in the area, where living conditions are better even if they must continue to work in the city. On the other hand, this progress in the area attracted the homeless people since it is easier than before to find food 
Table 6: Comparison of data on development.

\begin{tabular}{lccccc}
\hline $\begin{array}{l}\text { Questions } \\
\text { (variables) }\end{array}$ & $\begin{array}{c}\text { Vari } \\
(33)\end{array}$ & $\begin{array}{c}\text { Kalivia } \\
(37)\end{array}$ & $\begin{array}{c}\text { Koropi } \\
(75)\end{array}$ & $\begin{array}{c}\text { Markopoulo } \\
(47)\end{array}$ & $P$-values \\
\hline $\begin{array}{l}\text { Job satisfaction } \\
\text { Satisfaction from roads }\end{array}$ & $2.08 \pm 0.17^{*}$ & $2.00 \pm 0.14$ & $2.14 \pm 0.12$ & $2.05 \pm 0.12$ & 0.872 \\
$\begin{array}{l}\text { Adequacy of mass } \\
\text { transportation }\end{array}$ & $2.00 \pm 0.10$ & $1.76 \pm 0.13$ & $2.26 \pm 0.11$ & $1.79 \pm 0.11$ & 0 \\
$\begin{array}{l}\text { Satisfaction from } \\
\text { green areas }\end{array}$ & $2.16 \pm 0.09$ & $2.29 \pm 0.0899$ & $2.30 \pm 0.068$ & $2.50 \pm 0.0781$ & 0.027 \\
$\begin{array}{l}\text { Sustainable city } \\
\text { Illegal construction }\end{array}$ & $2.88 \pm 0.066$ & $2.94 \pm 0.0410$ & $2.85 \pm 0.055$ & $2.90 \pm 0.0458$ & 0.456 \\
Local development & $2.96 \pm 0.12$ & $2.14 \pm 0.0857$ & $2.89 \pm 0.0432$ & $2.93 \pm 0.0401$ & 0 \\
Over-populated region & $1.92 \pm 0.11$ & $2.41 \pm 0.0857$ & $2.89 \pm 0.043$ & $2.93 \pm 0.0402$ & 0 \\
\hline
\end{tabular}

$*$ Mean \pm SD.

and possible shelters. Therefore, socio-economic and demographic changes have increased the social and cultural diversity of these areas. Since the demand for housing has increased, local people sell their farms as valuable residential land and earn money that can be invested or consumed, which changes the lifestyle and brings new values to the local population. As population and service sectors grow significantly at the expense of agriculture, there is environmental pollution since the infrastructure for sewer, plumbing and litter recycling is not adequate to lever this extended increase.

It was demonstrated that the application of policies and programmes in east Attica had a significant effect on the sectors of enterprises, transport networks, on social welfare such as help at home for elders and children daycare and playgrounds. These sectors determine the sustainability of a city as stipulated by the European Union.

It is important for this area to formulate suitable policy and programmes to ensure local sustainable development. These policies must suggest specific constraints for population increase to avoid environmental deterioration, to specify the residential area and to promote vocational programmes in order to increase employment, to encourage environmentally friendly activities, to introduce social programmes that will help the homeless and special needs persons and most importantly to create the necessary infrastructure in the area.

\section{REFERENCES}

[1] Young, F., Reactive subsystems. American Sociological Review, 35, pp. 297-307, 1971.

[2] Munroe, D.K., Croissant, C. \& York, A.M., Land use policy and landscape fragmentation in an urbanizing region: assessing the impact of zoning. Applied Geography, 25, pp. 121-141, 2005.

[3] Vias, A.C., Mulligan, G.F. \& Molin, A., Economic structure and socioeconomic change in America's micropolitan areas, 1970-1997. The Social Science Journal, 39, pp. 399-417, 2002.

[4] Theodoropoulos, H., Review of rural/urban problem from an interdisciplinary perspective. Mediterranean perspectives and proposals. Journal of Economics, Agriculture and Environment. MEDIT, 3, pp. 24-32, 1999. 
[5] MacCannell, D., Series Guide to "The Tourist”, BBC Publications: London, 1995.

[6] Cano, C.R., Carrillat, F.A. \& Jaramillo, F., A meta-analysis of the relationship between market orientation and business performance: evidence from five continents. International Journal of Research in Marketing, 21, pp. 179-200, 2004.

[7] Fromard, F., Vega, C. \& Proisy, C., Half a century of dynamic coastal change affecting mangrove shorelines of French Guiana. A case study based on remote sensing data analyses and field surveys. Marine Geology, 208, pp. 265-280, 2004.

[8] Rodriguez, L.C. \& Pascual, U., Land clearance and social capital in mountain agro-ecosystems: the case of Opuntia scrubland in Ayacucho, Peru. Ecological Economics, 49, pp. 243-252, 2004.

[9] Crecente, R., Alvarez, C. \& Fra, U., Economic, social and environmental impact of land consolidation in Galicia. Land Use Policy, 19, pp. 135-147, 2002.

[10] De Sousa, C.A., Turning brownfields into green space in the city of Toronto. Landscape \& Urban Planning, 948, pp. 1-18, 2002.

[11] Jo, J.C. \& Adler, S., North Korean planning, urban changes and regional balance. Cities, 19(3), pp. 205-215, 2002.

[12] Williamson, I.P., Land administration "best practice" providing the infrastructure for land policy implementation. Land Use Policy, 18, pp. 297-307, 2001.

[13] Gar-on Yeh, A. \& Wu, F., The transformation of the urban planning system in China from a centrally-planned to transitional economy. Progress in Planning, 51(3), pp. 167-252, 1999.

[14] Owusu, F., Pragmatism and the gradual shift from dependency to neoliberalism: the World Bank, African leaders and development policy in Africa. World Development, 31(10), pp. 1655-1672, 2003.

[15] Skinner, M.W., Joseph, A.E. \& Kuhn, R.G., Social and environmental regulation in rural China: bringing the changing role of local government into focus. Geoforum, 34, pp. 267-281, 2003.

[16] Gatrell, J.D. \& Jensen, R.R., Growth through greening: developing and assessing alternative economic development programmes. Applied Geography, 22, pp. 331-350, 2002.

[17] Kennedy, J.J., Thomas, J.W. \& Glueck, P., Evolving forestry and rural development beliefs at midpoint and close of the 20th century. Forest Policy and Economics, 3, pp. 81-95, 2001.

[18] Firman, T., The restructuring of Jakarta metropolitan area: a "global city" in Asia. Cities, 15(4), pp. 229-243, 1998.

[19] Nghi, D.Q. \& Kammeier, H.D., Balancing data integration needs in urban planning, a model for Ha Noi City, Viet Nam. Cities, 18(2), pp. 61-75, 2001.

[20] Zhang, B., Assessing the WTO agreements on China's telecommunications regulatory reform and industrial liberalization. Telecommunications Policy, 25, pp. 461-483, 2001.

[21] Haines, A. Informed choices for attaining the millennium development goals: towards an international cooperative agenda for health-systems research. Lancet, Public Health, 364, pp. 997-1003, 2004.

[22] Huot, I., Paradis, G. \& Ledoux, M., Effects of the Quebec Heart Health Demonstration Project on adult dietary behaviours. Preventive Medicine, 38, pp. 137-148, 2004.

[23] Deng, F.F. \& Huang, Y., Uneven land reform and urban sprawl in China: the case of Beijing. Progress in Planning, 61, pp. 211-236, 2004.

[24] Smith, D.J., Patronage, Per diems and the "workshop mentality": the practice of family planning programs in southeastern Nigeria. World Development, 31(4), pp. 703-715, 2003.

[25] Shiffman, J., The construction of community participation: village family planning groups and the Indonesian state. Social Science \& Medicine, 54, pp. 1199-1214, 2002. 
[26] Shiffman, J., Skrabalo, M. \& Subotic, J., Reproductive rights and the state in Serbia and Croatia. Social Science \& Medicine, 54, pp. 625-642, 2002.

[27] Pobutsky, A.M., Economics and fertility: changing family structure among Chamorros on the Island of Guam. History of the Family, 6, pp. 95-123, 2001.

[28] Midgley, J.L., Shucksmith, D.M., Birnie, R.V., Geddes, A., Bayfield, N. \& Elston, D., Rural development policy and community data needs in Scotland. Land Use Policy, 22(2), pp. 163-174, 2005.

[29] Simon, C.J. \& Nardinelli, C., Human capital and the rise of American cities, 1900-1990. Regional Science \& Urban Economics, 32, pp. 59-96, 2002.

[30] Simon, C.J., Human capital and metropolitan employment growth. Journal of Urban Economics, 43, pp. 223-243, 1998.

[31] Azari, R. \& Pick, J.B., Technology and society: socioeconomic influences on technological sectors for United States countries. International Journal of Information Management, 25, pp. 21-37, 2005.

[32] Berdeguè, J.A., Ramirez, E., Reardon, T. \& Escobar, G., Rural nonfarm employment and incomes in Chile. World Development, 29(3), pp. 411-425, 2001.

[33] May, R., Rex, K., Bellini, L., Sadullah, S., Nishi, E., James, F. \& Mathangani, A., UN habitat indicators database: evaluation as a source of the status of urban development problems and programs. Cities, 17(3), pp. 237-244, 2000.

[34] Blassingame, L., Sustainable cities: oxymoron, utopia, or inevitability? The Social Science Journal, 35, pp. 1-13, 1998.

[35] AtKisson, A., Developing indicators of sustainable community: lessons from sustainable Seattle. Environmental Impact Assessment Review, 16, pp. 337-350, 1996.

[36] Burnette, J., Testing for occupational crowding in eighteenth-century, British agriculture. Explorations in Economic History, 33, pp. 319-345, 1996.

[37] European Commission, Sustainable Development in the Urban Union: Action Plan, Brussels, 1998.

[38] European Commission, The Structural Funds and the Coordination Thereof with the Cohesion Fund - Plan of Directives for the Programmes 2000-2006, Brussels, 1999.

[39] Mitoula R., Sustainable Regional Development in E.U. \& Reshaping of Greek Urban Environment, STAMOULI: Athens, 2006.

[40] Seabrooke, W., Yeung, S.C.W., Ma, F.M.F. \& Li, Y., Implementing sustainable urban development at the operational level (with special reference to Hong Kong and Guangzhou). Habitat International, 28, pp. 443-466, 2004. 